\title{
İşte Benim Kimliğim: Moda ve Medyanın Kadınların Kimlik İnşası ve İdeal Beden Söylemlerindeki Rolü Üzerine
}

\author{
Mine İmren \\ Uludağ Üniversitesi Fen-Edebiyat Fakültesi, Psikoloji Bölümü, Bursa \\ mimrenn@uludag.edu.tr \\ ORCID ID: https://orcid.org/0000-0003-0660-5396
}

\begin{tabular}{|c|c|c|}
\hline \multicolumn{3}{|c|}{ Derleme } \\
\hline Geliş Tarihi: $\quad 15.09 .2017$ & Revize Tarihi: $\quad 15.12 .2017$ & Kabul Tarihi: \\
\hline
\end{tabular}

\section{Attf Bilgisi}

İmren, M. (2018). İşte Benim Kimliğim: Moda ve Medyanın Kadınların Kimlik İnşası ve İdeal Beden Söylemlerindeki Rolü Üzerine, Ahi Evran Üniversitesi Sosyal Bilimler Enstitüsü Dergisi, 4(1), 103-111. Doi: 10.31592/aeusbed.338524

\section{ÖZ}

Günümüz görsel dünyasında imgeler oldukça büyük önem taşımaktadır. İnsanoğlu giyinmeye başladığından bu yana, giysi ve aksesuarları ile kendilerine dair bilgileri aktarabildikleri küçük ve güçlü bir imge dünyası sunmuştur. Moda da kültüre veya döneme göre değişebilen giysi ve aksesuarlar ile bu anlamda bireylerin iletişim araçlarından biri haline gelmiştir. Ancak, moda özellikle kadınların hem giysileri ile yansıttıkları kimliklerini hem de bedenleri ile ilgili algılarını sürekli manipüle eden bir araç haline dönüşmüş bulunmaktadır. Günlük yaşamda bireyler, özellikle de kadınlar bedenin olması gerektiği düşünülen ideal şekline dair normlara, medya aracılığı ile açık veya örtük bir şekilde maruz kalmaktadır. Tüm bunlar bir arada ele alındığında ise, medya ve moda işbirliğinin kadının beden imgesi ve kimlik inşasındaki rolü literatürde ilgi çeken ve incelenmeye değer bir başlık olarak karşımıza çıkmaktadır. Bu neden ile bu çalışmada, moda ve medya işbirliğinin kadınların ideal beden söylemlerini içselleştirmelerindeki ve giysi ve aksesuarlar üzerinden kendi kimliklerini inşa etmeleri üzerindeki olası rolü, alan yazın kapsamında incelenerek değerlendirilmiştir.

Anahtar kelimeler: moda, ideal beden, medya, kimlik

\section{That's My Identity: On the Role of The Fashion and Media on Women' Construction of Identity and Discourses of İdeal Body}

\begin{abstract}
Images are very important in today's visual World. They have served as a mini-yet-mighty image world which humankind is able to convey information about themselves via their clothes and accessories. In this sense, fashion with its clothes and accessories that vary depending on the culture and era, has turned into a communication vehicle among individuals. However, especially for women, fashion has transformed into a vehicle both manipulating their identity reflected by clothes or their body perception. In daily life, especially women are exposed to thoughts about ideal body shape norms either explicitly or implicitly by the media products, owing to the technological era. Taken into consider all of these, the topic of collaboration of fashion and media on women' body image and identity construction became an interesting and remarkable topic in the literature. In this review, it is argued that the role of collaboration of fashion and media on women's identity construction and internalization of ideal body perception.
\end{abstract}

Key words: fashion, ideal body, media, identity

\section{Giriş}

Moda, sürekli değişen giysi ve aksesuarları içeren bir alan olmanın dışında; kişilere sahip oldukları ürünlerle nasıl görünecekleri, nasıl hissedecekleri konusunda sunduğu etiketlerle bir nevi yeni kimlikler sunuyor gibi görünmektedir. Örneğin, çeşitli giysi ve aksesuar markalarına ait reklam sloganlarında veya o yılın modası ile ilgili soru yöneltilen modacıların konuşmalarında, belirli türde ürünler için "içinizdeki seksi kadını ortaya çıkaracak" ya da "içinizdeki çılgın kadına hitap ediyor" gibi örnekler kaynağ 1 belirsiz bir şekilde zihinde canlanabilmektedir. Aynı şekilde moda ürünlerinin belirli görünüşe sahip bedenlerde (zayıf, uzun gibi) sergilenmesi veya yine modacıların giysi ve aksesuarları kullanarak kadınların nasıl daha ince ve/veya daha uzun görünmeleri gerektiği ile ilgili yorumları, olması gereken ideal bir bedene vurgu yapmaktadır. Çeşitli medya araçları ile (TV, dergi, internet 
siteleri vs.) insanlara ulaşan moda görselleri özellikle kadınları hedef almakta ve kadınların da farkında olarak veya olmayarak maruz kaldıkları bu görsellerin sunduğu, istenilen kimliğin nasıl yansıtılacağı ve ideal bedene ulaşma veya bedeni ideal gösterme hakkındaki tüyolardan etkilendikleri bilinmektedir (Baudrillard, 2012; Fouts ve Burgraf, 1999). Grogan (1999), TV'nin özellikle de ideal beden hakkında çok fazla uyaran içerdiğini ve böylece bu anlamdaki etkisinin de kaçınılmaz olacağını dile getirmektedir (Aslan, 2001; Oğuz, 2005). Örneğin, son zamanlarda televizyon ekranlarında yılın modası olarak belirlenen ürünlerin özelliklerine dair tanıtıcı bilgilerin aktarıldığı çeşitli moda programları veya moda yarışma programlarında kullanılan söylemler kadınların giysi ve aksesuar tercihlerinden bahsedilirken kullanılan söylemler hem ideal bedeni vurgulamakta hem de kimlik inşasına zemin hazırlıyor gibi görünmektedirler.

Kadınların kimlik inşasının moda ile ilişkisi çok tartışılmasına rağmen az araştırılan bir konudur (Yağlı, 2012). Değişenin sadece gardıroptaki giysiler olmadığı, aynı zamanda kadınların kimliğinin de giysilerle birlikte değişim gösterdiği düşünülmektedir (Guy ve Banim, 2000). King (2004) kimliklerin giysiler yoluyla değiştiğini veya sabitlendiğini öne sürmektedir. Bu düşünce de; giysiler ile birlikte değiştiği öne sürülen kimliğin, giysi tercihinin değişmediği, yani benzer görünüm sağlayan giysilerin sıklıkla tercih edildiği durumda sabit hale geldiği yorumuna açık görünmektedir. Giddens (1991) ve Shellling (1993) gibi düşünürler ise, beden de aynı zamanda kimliği yansıtacak bir araç niteliğine sahip olduğunu düşünmektedir (akt. Oğuz 2005).

$\mathrm{Bu}$ açılardan bakıldığında giysiler, ideal beden imajı ve kimlik arasında sıkı bir ilişki olduğunu düşündürmektedir. Bireyler içinde bulundukları topluma ait kültür, değer yargısı, ideoloji gibi çeşitli birimler tarafından şekillendirilmiş bir dil kullanmakta ve baskın olan değerler dil aracılığı ile dayatılabildiği gibi, görsel medya tarafından da desteklenmektedir (Bedük, 2009). Bu bağlamda bu derlemenin amacı da, kadınların ideal beden algıları ve kimlik inşası üzerine görüş ve çalışmaları moda ve medya iş birliği temelinde ele almaktır.

\section{Moda ve Kimlik}

Moda, beden ve güzellik odağında kimlik, statü, beğeni gibi kavramları hem dönüştürmekte (Yağl1, 2012) hem de bunlar tarafindan şekillenebilmektedir. Bu dönüşümlü etkileşim, tarihte moda ile ilgili değişimlere bakıldığında en iyi şekilde görülebilmektedir. Modanın tarihi hakkında iki görüş bulunmaktadır (Barbarosoğlu, 2009'dan akt., Eke, 2013). Bu görüşlerden biri, moda denen kavramı reddederek moda denen şeyin aslında birtakım amaçlarla kullanılmış olan semboller olduğunu dile getirmekte, diğer görüş ise modayı sanayi devrimi ile birlikte ortaya çıkmış ve yüksek zümreyi sınıfsal olarak diğer bireylerden ayrı tutan görsel bir öğe olarak görmektedir (Daynes, 2007'den akt., Eke 2013). Moda'nın döneme ait dil üzerinden nasıl kullanıldığı ve meşrulaştırıldığı oldukça ilgi çekicidir. Moda kelimesi, "mod" kelimesinden türeyerek tüm diziyi temsil eden tepe noktası anlamında kullanılmıştır (Gürsoy, 2004'ten akt., Eke, 2013). Kelimenin türetilmiş olduğu kökün anlamına bakıldığında, soyluların giysiler aracılığıyla ve moda söylemi üzerinden kendi üst konumdaki statüsünü ilan etmesi ve vurgulaması olarak yorumlanabilir. Özetle, moda Avrupa'da tarih boyunca toplumsal roller, statü, hiyerarşi gibi kavramlarda belirginleştirme aracı olarak kullanılmıştır.

Türkiye'de tarihsel açıdan bakıldığında, Osmanlı döneminde giysi ve aksesuarlar daha çok ayırt edicilik (Yeniçeri-Kazasker gibi) üzerinden şekillenmiş ve bu amaçla kullanılmıştır (İlyasoğlu, 1994'ten akt., Eke, 2013). Cumhuriyet döneminde ise k1lık kıyafet kanunu gibi yasalarla getirilen düzenlemeler beraberinde küreselleşmeye katılımı getirmiştir (Eke, 2013). Kılık kıyafete dair yasal düzenlemeler sonrasında çeşitli kaynak veya belgesellerde görülen fotoğraflar Cumhuriyet Dönemi kadınlarının ve aynı dönem Avrupalı kadınların giyimlerinin benzer olduğunu ortaya koymaktadır. Dilimizde ise moda daha çok geçici bir yenilik anlamında kullanılmaktadır (TDK, b.t.). Bu şekilde bakıldığında yenilik olarak görülmesinin yanında geçiciliği vurgulanmaktadır.

Küreselleşme ile birlikte artık giysiler statü, rol, hiyerarşik konum belirleme anlamında ikinci plana atılmış ancak beden ve kimlik temsili açısından oldukça önemli olmuştur (Eke, 2013). İçinde bulunduğumuz yüzyılda moda, kendi içinde alt gruplara ayrılmış ve bireylerin ait oldukları gruba uygun şekilde kendilerini temsil etmesini sağlayacak farklı nesnelerle çeşitlenmiştir. Bu anlamda düşü- 
nüldüğünde moda, hem sınıfların ayrımını hem de sınıf içi farklılığı temsilen sembolik bir araca dönüşmüştür (Yağl1, 2012). Bu semboller kişilerin kendileri ve diğerlerinin kimliklerini bu görüngüler üzerinden yansıtmasını ve anlamasını sağlamışıtır. Böylelikle giysiler de kimlik ile bağdaştırılmıştır (Türkoğlu, 2000'den akt., Yağl1, 2012). Bu şekilde beden aracıllğı ile giysinin kimliği temsili, değiş̧en beğenilerle birlikte kimliği de bir nevi değişime uğratmaktadır (Yağlı, 2012). Moda tüketim açısından ele alındığında da, tüketicilerin nesneleri hem kendi kimliklerini belirleme ve kendini bir eğilime ait olarak tanımlama açısından hem de bunu diğerlerine yansıtma açısından da aracı olmaktadır (Binay, 2010).

Sonuç olarak, sürekli değişen moda ile dönemsel olarak kimlik tanımları da değişime uğramış ve moda bireylerin kendilerini ortaya koyma aracı olmuş gibi görünmektedir. Görselliğin ön plana çıktığı günümüzde, giysiler insanların kendilerini ifade etmede kullandığı dillerden biri haline gelmiştir. Öyle ki, giysiler modaya uyumuna bakılmaksızın kişinin kimliğini yansıtan bir araç olmuştur (Eke, 2013; Oğuz, 2005). Özetle, Tungate (2006)' in de dile getirdiği gibi moda uğruna satın alınanlar aslında kimlikler olmuştur (akt. Eke, 2013). Bu görüşler en açık bir biçimde günümüz moda yarışma programlarında gözlenmektedir. Bu yarışmalarda kadınlar giysi ve aksesuarları ile modaya uygunluklarının yanı sıra her seferinde farklı bir "tarza" bürünme durumlarına göre jüri ve diğer yarışmacılar tarafından değerlendirilmektedir. Programda kadınların giyim ve aksesuar tercihleri ile sahip oldukları ve dış görünüşlerine yansıttıklarının farklı "tarzlar" olduğu söylense de değerlendirme yapılırken kullanılan ifadeler ("karşımda ă̆ır başll/ç̧ılgın/baştan çıkaran/ciddi/rüküş/hanım hanımcık vs. bir kadın görüyorum" gibi) kişilerin bu giysilerle birlikte sadece bir "tarza" değil, aynı zamanda bir kimliğe sahip olduklarını göstermektedir. Moda üzerine olan bu yarışma programları, kişilere tercih ettikleri giysi ve aksesuarlar ile çeşitli kimlikler edinme ve bu kimlikleri değiştirebilme konusunda imkân sunmaktadır. Böylece, kişiler giysiler üzerinden ortaya koydukları söylemleri ile kimliklerini inşa etmektedirler.

\section{İdeal Beden}

Çocuğun kendi bedeninin farkına varması ile başlayan beden algısı, diğerleriyle karşılaştırma süreçlerinden geçerek gelişir ve ömür boyu sürer (Özaltın, 2003). Bedenler arasındaki bu kıyaslama temelde ideal beden imajının bir ürünü olarak görülebilir. Çünkü Özaltın 'a göre (2003) ideal beden, bedenin görünmesi gerektiği düşünülen zihinsel bir idealle kıyaslanmasını içermektedir. Beden imajı kişinin bedeni hakkındaki zihinsel imgelemi (Eke, 2013) olarak ele alındığında; kültürün, modanın veya medyanın popüler olanı ve dolayısıyla ideal olanı belirlemesi nedeni ile ideal beden imajını etkileyebilmektedir (Öner, Telatar ve Yeşildağ; 2015; Özaltın, 2003; Ünüvar, 2006'dan akt., Hamurcu,). Guy ve Banim (2000) çalışmalarında, kadınların "olmak istedikleri kadın" hakkındaki görüşlerini dile getirirken kullandıkları kelimeler üzerinden kendi kimliklerini ve bedenlerini nasıl etiketlediklerini açık bir şekilde göstermiş̧ir. Giysi, bedeni koruyan, saran ve kimliği yansıtan işlevlerinin dışında, aynı zamanda bedende istenen kısımlarının vurgulanarak veya gizlenerek yönlendirilebilmesine imkân sağlayan bir nesnedir (Guy ve Banim, 2000). Giysinin bu şekilde yönlendirilmesi idealize edilmiş beden imajını yansıtmaya olanak verebilir. Örneğin, ideal beden tarifine uygun görünümü sağlayacak giysiler tercih edilebilir. Guy ve Banim (2000), modanın kadın bedeni üzerinde çeşitli değişimlemeler yaptı̆̆ını öne sürmektedir. Günümüzde moda bu anlamda ele alındığında sadece giyim kuşam ile sınırlı kalmamakta, aynı zamanda beden ile ilgili fiziksel özellikleri de çoktan kapsamına almış gibi görünmektedir (Eke, 2013). Böylece, moda ile birlikte sadece giysiler değil bedensel beğeniler de değişime uğramaktadır (Yağlı, 2012).

Foucault (2007), bedenin iktidar tarafından şekillendirildiği üzerinde durmaktadır, ancak günümüzde bedenin şekillendirildiği yegâne mekân ekran gibi görünmektedir (Kınak, 2012). Bu nedenle, ideal bedeni şekillendirenin sadece moda olmadığı açıkça gözlenebilmektedir. Toplumsal olarak bazı beden imajlarının ideal olarak benimsenmesi medya aracılığ ile dayatılmaktadır (Stice, SchupakNeuberg, Show, Shaw ve Stein 1994). TV hemen her evde olan bir medya arac1 olduğundan her konudaki etkiyi yayma açısından oldukça etkili görünmektedir. Kadınlar, erkeklere göre ideal beden imaj1na daha fazla konu olmakta ve medya üzerinden veya kültürel olarak bu konuda daha fazla norma maruz kalmaktadır (Lin, 1998). Böylece kadınlar, karşılaştırma yapabilecekleri daha fazla ideal beden imajına maruz kalmaktadır. Bu durum, zayıf bedeni ideal olarak gören kadınların daha fazla medya imgeleriyle karşılaştırma yaptıklarını ortaya koyan çalışmalarca desteklenmektedir (Aslan, 2001). 
Ayrıca, moda hakkındaki yarışma programlarında kadınlar giysi ve aksesuar tercihleri ile bedenlerini ideal beden olarak görülen "ince ve uzun kadın" görünümünden ne denli uzaklaştırdıkları konusunda şişman ve kısa göründükleri gerekçesiyle başarısız bulunmakta ve ideal beden görünümüne yaklaştıkları zamanlarda tercihlerinin kendilerini "uzun ve ince" gösteriyor olduğu gerekçesiyle başarılı bulunarak ödüllendirilmektedir. Böylece, ideal olan beden konusundaki söylemlerle, modanın sadece bedenin dişıyla değil bedenin kendisiyle de ilgili olduğu da ortaya konmaktadır. Sözü geçen programlarda yarışmacıların söylemleri ve davranışları hem kültür hem de iktidar görüşleri tarafından da etkileniyor gibi görünmektedir. Şöyle ki, yarışmacılar bazen giysilerini sergileyerek kimliklerini ve ideal bedeni yansitma konusunda zaman zaman beden hatlarının veya toplum tarafindan mahrem olarak nitelenen beden bölgelerinin dekolte ile gösterilmesi gibi durumlarda eleştirilebilmekte ve özellikle buna dikkat edildiği davranışsal olarak (program ekibi tarafından şal verilmesi gibi) da açıkça sergilenmektedir. Böylece kişiler ideal bedenin nasıl olması gerektiği ve nasıl ideal görünülebileceği konusundaki söylemleri ile ideal beden normlarını belirlemekte ve meşrulaştırmaktadırlar.

Medyanın ideal beden algısı oluşturmadaki çabası her zaman açık bir şekilde olmayabilir. $\mathrm{Bu}$ durum, benzer görsellikte kadınların kullanılması gibi örtük şekillerde de gerçekleşebilir (Oğuz, 2005). Ayrıca, TV programlarında görülen ideal bedene sahip olan ve olmayan kadınların nitelendirildiği sıfatlar, bağlam içinde karşılaştıkları olaylar ve çevrelerinden gördükleri muameleler de örtük olarak veya alenen seyircilere ideal beden imgesini aş1liyor görünmektedir. Cohen (1991) beden idelinde belirlenen normların sahip oldukları çeşitliliğginin (boy, kilo, ten rengi gibi) yanı sıra, değişkenliğinden de söz ederek (Coşkuner, 2003'ten akt., Hamurcu ve diğer., 2015), güzellik standartlarının dönemsel hatta kültürel olarak farklılaşabilme (Diedrichs ve Lee, 2010) niteliğine de vurgu yapmaktadır. Benzer şekilde Baudrillard (2012) da geçmişten günümüze çeşitli sınırlandırmalara, şekillendirmelere konu olmuş bir nesne olan bedenin beğenisinde dönemsel farkl1l1klar görüldüğünü belirtmiştir. Örneğin, geçmişten günümüze Türk filmleri göz önüne getirildiğinde başrol oyuncularının git gide daha ince kadınlardan tercih edildiği açıkça fark edilmektedir. Yani, dönemsel olarak değişebilen beden idealleri çeşitli medya araçları ile dayatılmaya çalışılmaktadır. Böylece, medya üzerinden övülerek ideal olarak sunulan bedenler ve yerilerek kaçınılması gerekliliği vurgulanan ideale uzak bedenler kadınlar tarafından içselleştirilebilmektedir (Eşiyok-Sönmez, 2015). Örneğin dergilerde kullanılan modellerin, kadınların kendi beden imgelerine dair tutumlarını olumsuz yönde etkilediği çeşitli çalışmalarca ortaya konmuştur (Dittmar, 2009; Grabe Ward ve Hyde, 2008; Groesz, Levine, Murnen, 2002; Harper Tiggeman, 2008; Levine ve Chopman, 2011; Want ve Saiphoo 2016; Yamamiya, Cash, Melnyk, Posavac ve Posavac, 2005). Medya aracılığı ile sunulan imgeler kişilerin kendilerini modelle karşılaştırması ve modelin ideal bedenini içselleştirmesi sonrası kendi bedenini ideale uzak olarak nitelendirerek memnuniyetsizlik duymasına neden olmaktadır (Engeln-Madox, 2005). Genç kadınlarla yürütülen bir çalışmada dergilerdeki model resimlerini inceledikten sonra katılımcıların \%47'si zayıflamayı düşündüğünü ve \%69'u ise beden imajına dair tutumunun olumsuz yönde değiştiğini belirtmiştir (Field, Cheung, Wolf, Herzog, Gortmaker ve Coldtz, 1999). Ayrica medyada ortalama veya ideale uzak bir beden görselinin, bireylerin kendi benden imgelerini olumlu yönde etkileyebildiğini gösterilmiştir (Diedrichs ve Lee 2010; Holmstorm, 2010).

Günümüzde ise, medyanın etkileri konusundaki bilinçlenme ile birlikte, kadınlar bu etkilerin farkında oldukları ve bu etkiye ciddi bir direniş göstereceklerini ortaya koydukları "beden olumlama hareketi" sosyal medyada hızla yayılmıştır (Kayış, 2017). Bu hareket genel hatlarıyla medya ve moda gibi etkenlerin kadın bedenini yaftalama ve idealize etme çabası karşısında, tüm bedenlerin kendi başlarına ideal olduğunu ve beden üzerindeki söz hakkının da sadece bedenlerin sahipleri olan kadınlara ait olduğunu vurgulamaktadır.

\section{Sonuç, Tartışma ve Öneriler}

Moda değişken doğası ile özellikle kadınların hem giysileri ile yansıttıkları kimliklerini hem de bedenleri ile ilgili algılarını sürekli manipüle etmektedir. Günlük yaşamda bireyler, medya aracılığı ile özellikle ideal beden şekli ile ilgili normlara açık veya örtük bir şekilde maruz kalabilmektedir. Televizyonda yayınlanan çeşitli moda programlarının da modanın ortaya koyduğu bu dinamiklerin bir aracısı olduğu düşünülmektedir. Bahsi geçen moda programlarına katılan kadınların kullanılan söy- 
lemler aracılığ ile kimlikler inşa ettikleri ve aynı zamanda söylemleri belirli şekildeki bedenleri idealize etme amacı ile kullanabildikleri gözlemlenmektedir. Medyanın da dönemsel olarak moda olan giysi ve aksesuarlar dışında ideal olarak sunduğu bedenler ile kadınların beden algısındaki etkin rolü çeşitli çalışmalarca da ortaya konmuştur. Kadınlar, medyanın kendisine malzeme edindiği kadın bedeni üzerine yapılan dayatmalardan çokça etkilenmektedir. Ancak, sosyal medyada başlayan ve hızla yayılan "beden olumlama hareketi" ile birlikte kadınlar özellikle bedenleri konusundaki medya tutsaklığına karşı çıkmaya başlamıştır.

Sonuç olarak, moda ve medya ortaklığı hem kadınların kimlik inşasında hem de bedenlerinde fazlasıyla söz sahibi gibi görünmektedir. Moda sadece teoride giysi ve aksesuarlar temelinde bir akımı temsil etmektedir. Ancak pratikte, sadece dönemsel olarak değişen giysi ve aksesuarın değil ideal olan bedenin de belirleyicisi olmuştur. Ayrıca moda sunduğu nesnelerin çeşitli birleşimleri ile bir kimlik üst kategorisi de oluşturabilmektedir. Giysi ve aksesuarlar bireylere adeta bir kimlik kataloğu sunuyormuş ve bu kataloğun kullanım kılavuzu ise medya ve özellikle de modaya dair programların tekelindeymiş gibi görünmektedir. Alan yazın göstermektedir ki, herhangi bir medya türü aracılığı ile kadınlar ideal bedene sahip olma, modanın sundukları ile vadettiği çeşitli kimlikler inşa etmeleri konusunda bir baskı altına alınmıştır. Bu durum özellikle genç kızların hem giysi, aksesuarlar gibi metalara gereğinden çok daha fazla önem atfetmesi, hem de bedenlerinden ideal beden ölçülerine yakınlığ ölçüsünde memnun olmaları anlamına gelmektedir. Bu nedenle, çeşitli çalışmalarla ortaya konmuş olan medyanın kadınlar üzerindeki dayatma gücünün kontrol edilmesi, kullanılan söylem ve görsellerin gözden geçirilerek denetlenmesi ve düzenlenmesinin oldukça önemli olduğu düşünülmektedir. 


\section{Kaynaklar}

Aslan, H. (2001). Beden imgesi ve yeme davranışı bozuklukları ile medya ilişkisi. Düşünen Adam, 14(1), 41-47.

Bedük, N. (2009). Gelenek, iktidar ilişkileri ve toplumsal cinsiyet temsillerinde melezleşme: Türk TV dizileri üzerine bir söylem analizi.(Yayımlanmamış Yüksek lisans Tezi). Yeditepe Üniversitesi Sosyal Bilimler Enstitüsü, İstanbul.

Binay, A. (2010). Tüketim vasıtasıyla oluşturulan postmodern kimlikler. Global Media Journal Turkish Edition, 1(1), 17-29.

Baudrillard, J. (2012). Tüketim toplumu söylenceleri/ yapıları. (H. Deliceçaylı ve F. Keskin, Çev.). (5.Basım). (Orijinal basım: 1970).Ayrınt1 Yayınları: İstanbul.

Chung, S. (2013). Clothing as 1dentity and gender in the merchant of venice. IPEDR, 68, 1-14.

Cohen A. (1991). Body image in the person with a stoma. Journal of Enterostomal Therapy 18, 68-71.

Crane, D. (2000). Fashion and its social agendas: Class, gender, and identity in clothing. University of Chicago Press: Chicago.

Çelik, H. ve Ekşi, H. (2008). Söylem analizi. Marmara Üniversitesi Atatürk Ĕgitim Fakültesi Eğitim Bilimleri Dergisi, 27, 99-117.

Dittmar, H. (2009). How do "body perfect" ideals in the media have a negative impact on body image and behaviors? Factors and processes related to self and identity. Journal of Social and Clinical Psychology, 28, 1-8.

Eke, N. P. (2013). Bedene müdahalenin bir yolu olarak moda ve medyada sunulan beden algist. (Yayımlanmamış Yüksek lisans Tezi). Selçuk Üniversitesi Sosyal Bilimler Enstitüsü, Konya.

Engeln-Maddox, R. (2005). Cognitive responses to idealized media images of women: The relationship of social comparison and critical processing to body image disturbance in college women. Journal of Social and Clinical Psychology, 24(8), 1114-1138.

Eşiyok Sönmez, E. (2015). Tüketim nesnesi olarak kadın bedenin inşasında estetik ürün reklamları: Cosmopolitan dergisi örneği. International Journal of Human Sciences, 12(2), 1131-1144.

Evecen, A. (2015). Baudrillard'dan modern toplumlara özgü bir moda kavramı çözümlemesi. Sosyal Bilimler Dergisi, 2(5): 216-226.

Field, A. E., Cheung, L. Wolf, A. M., Herzog, D. B., Gortmaker, S. L. and Colditz, G. A. (1999). Exposure to the mass media and weight concerns among girls. Pediatrics, 103, e36-e36.

Foucault, M. (2007). Göz kamaştırıcı hayvan: İktidar, iktidarın gözü. (I. Ergüden, Çev.). Ayrıntı Yayınları, Seçme Yazılar 4: İstanbul.

Fouts, G. ve Burggraf, K. (1999). Television situation comedies: Female body images and verbal reinforcement. Sex Roles, 40, 473-481.

Guy, A. ve Banim, M. (2000). Personal collections: Women's clothing use and identity. Journal of Gender Studies, 9(3), 313-327.

Hamurcu, P., Öner, C., Telatar, B. ve Yeşildağ, Ş. (2015). Obez bireylerde benlik saygisı ve beden algısının değerlendirilmesi, Türk Aile Hekimliği Dergisi 19 (3),122 - 128.

Harper, B. ve Tiggemann, M. (2008). The effect of thin ideal media images on women's selfobjectification, mood, and body image, Sex Roles, 58(9), 649-657.

Holmstrom, A. J. (2004). The effects of the media on body image: A meta-analysis. Journal of Broadcasting \& Electronic Media, 48(2),196-217. 
İstanbul Kadın ve Kadın Kuruluşları Derneği (IKKADDER) (2013). Aile odaklı medya izleme ve değerlendirme projesi (AİLEMIZZ-P). http://www.ailemizprojesi.org/bu-tarz-programlar-bizimdegil/ Erişim tarihi:19 Ocak 2016.

Kayış, E. (2017, 13 Şubat). Beden olumlama hareketi. [Blog yazısı]. Erişim tarihi: 27 Temmuz 2017, https://catlakzemin.com/beden-olumlama-hareketi/

Kınak, G. (2012, Kasım). Sen Sustukça Bedenin Konuş(t)ur(ulur). Skopbülten, 2012(Kasım). Erişim tarihi: 27 Aralık 2015, https://www.e-skop.com/skopbulten/sen-sustukca-bedenin-konus-turulur/982

King, A. (2004). The prisoner of gender: foucault and the disciplining of the female body. Journal of International Women's Studies, 5(2), 29-39.

Lin, C. A. (1998). Uses of sex appeals in prime-time television commercials. Sex Roles, 38(5-6), 461 475.

Oğuz, G.Y. (2005). Bir güzellik miti olarak incelik ve kadınlarla ilgili beden imgesinin televizyonda sunumu. Selçuk İletişim, 4(1), 31-37.

Özaltın G. (2003). Beden imgesi değişimine yaklaşımlar. İstanbul Üniversitesi Florence Nightingale Hemşirelik Yüksekokulu Hemşirelik Dergisi, 51(8), 4-14.

Stice E., Schupak-Neuberg E., Show H. E. and Stein, R. I. (1994). Relation of media exposure to eating disorder symptomatology: An examination of mediating mechanisms. Journal of Abnormal Psychology,103, 836-840.

TDK, (b.t.). Moda. http://www.tdk.gov.tr. Erişim tarihi: 20 Aralık 2015

Vertanian, L. R., Giant, C. L. and Passino, R. M. (2001). Ally McBeal vs. Arnold Schwarzenegger: comparing mass media, interpersonal feedback and gender as predictors of satisfaction with body thinness and muscularity. Social Behavior and Personality, 29 (7), 711-772.

Want, S.C. and Saiphoo, A. (2017). Social comparisons with media images are cognitively inefficient even for women who say they feel pressure from the media. Body Image, 20,1-6.

Yağlı, F. (2012). Görsel kültür ve görsel imajın bir inşa alanı olarak modanın endüstriyel büyüsü. 0810 Ekim 2012 “1. Uluslararası Moda ve Tekstil Tasarımı Sempozyumu’nda sunulmuştur. http://edergi.akdeniz.edu.tr/index.php/akdenizsanat/article/view File/457/383 . Erişim tarihi: 25 Aralik 2015.

Yamamiya, Y., Cash, T. F., Melnyk, S. E., Posavac, H. D. and Posavac, S. S. (2005). Women's exposure to thin-and-beautiful media images: Body image effects of media-ideal internalization and impact-reduction interventions. Body Image, 2(1),74-80.

Yavuz, S. (2015, 13 Mart). Moda programları gençleri olumsuz etkiliyor! Milliyet. Erişim tarihi: 25 Aralık 2015, http://www.milliyet.com.tr/moda-programlari-gencleri-olumsuz-etkiliyor-pembenar yazardetay-aile-2029168/ 


\section{Extended Abstract}

\section{Introduction}

Fashion is not just a concept consisting of changing clothes and accessories; it also serves to generate labels shaping the norms of how to look like or feel, along which emerges the representation of women's identity. For instance, advertisements of many fashion brands include sentences about their products such as "It will unearth your inner sexy woman" or "It speaks to your wild-side" etc. Also, fashion puts an emphasis on the ideal body size by exhibiting clothes and accessories with tall and thin bodies. TV fashion shows Images about fashion reaching the large masses via kind of media (TV, magazine, web sites, etc.) addresses to women and affect them about how they can reflect their identity and have ideal body shape or show their body as ideal-like. Collaboration of media and fashion present women clothes, accessories, hair styles and more which is chosen as a favorite of the year. Nowadays, some shows started to televise about fashion on which women compete each other with their fashion style. The fashion competition shows' jury criticize women' choices of clothes and accessories and also their styles which is reflected by the choices. However the style which is criticized does not seem to just about appearance but also about identity. The jury when criticize a competitor says that kind of sentences: "You appear demure/pretty/crazy etc." and it means that the styles are not just representations of women' choices but also their identity. Also the other critisim of the jury is about competitors' body shape. If they look like nearly ideal (thin and tall body), they are rewarded with compliment and high points, otherwise they get severe criticism. The relationship between identity construction of women and fashion is not investigated much but it is much-discussed (Yağl1, 2012). The discussions emphasize that fashion make changes not on wardrops, but also identities (Guy ve Banim, 2000). Media also help fashion by presenting icons of ideal body, and affect women' body images. Therefore, it can be thought that there is a strong relationship between fashion, ideal body image and identity

\section{Fashion}

Fashion images which are communicated to individuals via different kinds of media tools (TV, websites, ads, etc.) are directed at women and it seems to be affecting them by serving cues with images about how they reflect the identity they should want, how they can have the ideal body or how they can achieve an ideal or almost ideal body. It is thought that fashion make change not only wardrobes but also identities (Guy and Banim, 2000). Although the relationship between fashion and women's identity is a issue that is discussed much, but investigated very few (Yağl1, 2012). Clothes and accessories became very important in terms of representation of body, identity, status and roles, but the importance has been pushed into the background with the globalization (Eke, 2013). Tungate (2006) verbalized impressively that purchased ones are not clothes or accessories but identities.

\section{Ideal Body}

Self-body perception begins with awareness of one's own body and lasts lifelong by comparing one's own body with others' (Özaltın, 2003). According to Grogan (1999), especially TV includes lots of stimuli about ideal body image and its effects seems to be inevitable (Oğuz, 2005; Aslan, 2001). ). Lots of investigations showed that women thought thin body as an ideal, compare their body with the models on the media more than their environment (Aslan, 2001). Some of the studies revealed that the models which have ideal body, effect women's attribution of self-body image adversely (Groesz, Levine, Murnen, 2002; Yamamiya, Cash, Melnyk, Posavac ve Posavac, 2005; Grabe Ward ve Hyde, 2008; Harper Tiggeman, 2008; Dittmar 2009; Levineve Chopman, 2011; Want ve Saiphoo 2016). Also some researches show that using images of average body sized models change individuals' self-body image positively (Diedrichs ve Lee 2010; Holmstorm, 2010). On the other hand, Field and others (1999) showed that $47 \%$ of teenage participants reports that they want to lose weight and 
$69 \%$ of them report that their self-body image attitudes changed negatively after having been exposed to visual stimuli of thin models. Fashion can cause teenagers to over-estimate materialistic expectations such as clothes and accessories and affect their satisfaction about their own body thereby.

\section{Result, Discussion and Suggestions}

As a sum, corporation of media and fashion has a voice not only women's construction of their identities but also their body image. This case, can cause teenagers to overrate meta such as clothes and accessories and affect their body satisfaction via the meta. Therefore, the power of the media which has been demonstrated in more than one way should be controlled by observing and reorganizing narratives and images used by the media. 